\title{
Acule Clinical and Angiographic Results With the New AVE Micro Coronary Stent in Bailout Management
}

\author{
Yukio Ozaki, MD, PhD, David Keane, MD, PhD, Peter Ruygrok, MD, \\ Pim de Feyter, MD, PhD, Simon Stertzer, MD, and Patrick W. Serruys, MD, PhD
}

To determine the feasibility and safety of deployment of this new stent, we deployed 28 AVE Micro stents in 23 native coronary artery lesions in 20 patients who developed acute or threatened closure after balloon angioplasty (BA). Ten stents were deployed in the left anterior descending artery, 10 in the circumflex, and 8 in the right coronary artery. Luminal dimensions were measured using a computer-based quantitative coronary angiographic analysis system (CAAS II). Stent deployment was successful in 27 of 28 attempts $(96 \%)$. In 1 patient with a threatened closure of the left anterior descending artery associated with proximal vessel tortuosity, attempted stent deployment was unsuccessful. The clinical course of the other 19 patients in whom stent deployment was successful was free of coronary reintervention, bypass surgery, and death. A myocardial infarction was observed in 2 patients $(10 \%)$, in 1 of whom the stent was implanted within 24 hours after the onset of acute myocardial infarction, and in the other acute vessel occlusion was present for 58 minutes before stent implantation. No subacute occlusion was observed. Event-free survival at 30 days after stent implantation was $85 \%$ (17 of 20 patients). Minimal

ne of the major risks associated with balloon angioplasty (BA) is acute or threatened closure of the coronary artery. When acute coronary occlusion persists after balloon dilatation, $20 \%$ to $40 \%$ of patients sustain a myocardial infarction and $4 \%$ to $8 \%$ of patients die. ${ }^{1-4}$ Several nonrandomized studies have suggested that deployment of the Wallstent, 5,6 Gianturco-Roubin stent, ${ }^{7-11}$ or Palmaz-Schatz stent ${ }^{12-14}$ may be of value in bailout management ${ }^{15,16}$ of acute or threatened closure after BA. A number of second generation stents have recently been developed and are currently entering the clinical arena. One of the most recently developed stents is the AVE Micro stent (sec Figure 1). This study reports early cxperience with the AVE Micro stent in the clinical arena. Clinical events up to 30 days (to cover both the period of in-hospital events and period of risk of subacute throm-

\footnotetext{
From the Catheterization Laboratory, Thoraxcenter, Erasmus University, Rotterdam, The Netherlands, and the Division of Cardiovascur lar Medicine, Stanford University Medical Center, Stanford, Connecticut. Dr. Ozaki is a recipient of a grant from Takeda Medical Research (Taisha ljol Foundation, Osaka, Japan. Dr. David Keane is a recipient of a travel grant from the Peel Medical Research Trust, London, United Kingdom. Manuscript received January 27, 1995; revised manuscript received and accepted May 11, 1995.

Address for reprints: Patrick $W$. Serruys, MD, PhD, Thoraxcenter, Erasmus University, P.O. Box 1738, 3000 DR Rotterdam, The Netherlands.
}

luminal diameter was $0.85 \pm 0.57 \mathrm{~mm}$ before and 1.19 $\pm 0.66 \mathrm{~mm}$ affer $\mathrm{BA}, 2.61 \pm 0.39 \mathrm{~mm}$ during balloon inflation, $3.26 \pm 0.46 \mathrm{~mm}$ during and $2.74 \pm 0.51 \mathrm{~mm}$ after stenting, $3.43 \pm 0.52 \mathrm{~mm}$ during balloon inflation after stenting (Swiss Kiss), and $2.85 \pm 0.48 \mathrm{~mm}$ after Swiss Kiss. Average percent diameter stenosis was reduced from $69 \%$ before through $56 \%$ after BA to $17 \%$ after stenting. During the initial stent implantation, stent recoil was $0.52 \pm 0.30 \mathrm{~mm}$ (16 $\pm 9 \%$ of minimal luminal diameter during stent inflation). A Swiss Kiss was performed in 14 stents with an average pressure of 14 $\pm 4 \mathrm{~atm}$, and residual stenosis was reduced from 2.55 $\mathrm{mm}$ ( $21 \%$ diameter stenosis) to $2.85 \mathrm{~mm}$ (15\% diameter stenosis) in these lesions. Angiographic success $(<30 \%$ residual diameter stenosis) was achieved in all stented lesions. The results of this early experience would indicate that the new AVE Micro stent may be deployed with a high procedural success rate and a minimal learning curve. Implantation of the stent for the bailout management of failed BA can be achieved with a low incidence of adverse cardiac events and a high angiographic success rate.

(Am J Cardiol 1995;76:112-116)

bosis) are reported as well as the acute angiographic results. Quantitative angiographic measurements were obtained at 7 intraprocedural phases: before primary BA, during primary balloon inflation, after BA at the time of acute or threatened vessel closure, during stent inflation, after stent deployment, during high-pressure intrastent balloon inflation (Swiss Kiss), and finally after Swiss Kiss, using a quantitative coronary angiographic analysis system (CAAS II).

\section{METHODS}

Patients: To determine the feasibility and safety of deployment of this new stent, we placed 28 AVE Micro stents in 23 native coronary artery lesions in 20 patients who developed acute or threatened closure after BA. The average age was $56 \pm 7$ years (range 45 to 68 ), and 17 patients were men. Thirteen patients had stable angina and the remaining 7 patients had unstable angina. ${ }^{17}$ of the 7 patients with unstable angina, 4 had Braunwald type II and 3 had type III angina. 17

Criteria of acute and threatened vessel closure: After $\mathrm{BA}$, lesion morphology was categorized according to the dissection criteria proposed by Huber et al, ${ }^{18}$ and coronary flow distal to the lesion was classified according to the Thrombolysis in Myocardial Infarction trial (TIMI) criteria. $^{19}$ Acute occlusion was defined as TIMI 0 flow. Threatened closure was defined as TIMI 1, 2, or 3 flow, 
with visible dissection type $\mathrm{C}, \mathrm{D}, \mathrm{E}$, or $\mathrm{F}$, or as dissection type A or B and TIMI 1,2, or 3 flow with a residual diameter stenosis of $>50 \%$. 18,19

Stent design: This short stent is characterized by a simple balloon-expandable deployment technique, and 0.008 -inch stainless steel struts with moderate radiopacity and a zigzag structure. The metallic surface area in the expanded state has been found in vitro to be $8.4 \%$ for the stent with a $3.5 \mathrm{~mm}$ diameter. This stent is composed of $4 \mathrm{~mm}$ welded and unconnected segments providing a range of lengths from 4 to $16 \mathrm{~mm}$ (Figure 1).

Balloon angioplasty and stent implantation: BA and stent deployment (Figure 1) were performed according to standard clinical practice by the femoral approach at the Thoraxcenter (Rotterdam, The Netherlands). The coronary stents were delivered on a premounted balloon catheter. The size of the balloon is $0.25 \mathrm{~mm}$ larger than the stent diameter to allow for stent recoil. Selection of the nominal stent size was determined to match the vessel reference diameter obtained from on-line quantitative angiographic measurement. Of the 28 stents used in 23 lesions, 9 had a $3 \mathrm{~mm}$ diameter, and 15 had a $3.5 \mathrm{~mm}$ and $4 \mathrm{a} 4 \mathrm{~mm}$ diameter. Of the 28 stents 7 were $4 \mathrm{~mm}$ in length, 17 were $8 \mathrm{~mm}, 2$ were $12 \mathrm{~mm}$, and 2 were 16 $\mathrm{mm}$. During primary BA, the nominal balloon diameter was $2.98 \pm 0.41 \mathrm{~mm}$, and the maximal inflation pressure given was $9.3 \pm 3.0 \mathrm{~atm}$. After initial deployment of the stent, high-pressure inflations $(14.6 \pm 3.5 \mathrm{~atm})$ to optimize stent expansion (Swiss Kiss) were obtained with balloons with $3.50 \pm 0.55 \mathrm{~mm}$ nominal diameter.

Anticoagulant therapy: At the beginning of the procedure, patients were given an intravenous bolus dose of $10,000 \mathrm{IU}$ of heparin, and subsequently $5,000 \mathrm{IU}$, as required, to maintain the activated clotting time of $>300$ seconds throughout the procedure. The postintervention anticoagulant regimen was conventional ${ }^{20}$ : One hour after removal of the femoral sheath, a heparin intravenous infusion was begun to maintain the activated partial thromboplastin time between 70 and 90 seconds until oral anticoagulant therapy (warfarin) had achieved a prothrombin time international normalized ratio of 2.5 to 3.5. Warfarin was prescribed for 3 months after stent implantation, and aspirin indefinitely. ${ }^{20}$

Quantitative coronary angiographic analysis: The new version of the CAAS II analysis ${ }^{21,22}$ was used to perform quantitative analysis. In the CAAS II analysis, which has previously been described elsewhere, $22-24$ the entire cineframe of $18 \times 24 \mathrm{~mm}$ is digitized at a resolution of $1,329 \times 1,772$ pixels. Correction for pincushion distortion is performed before analysis. Boundaries of a selected coronary segment are detected automatically. The absolute diameter (mm) of the stenosis is determined using the guiding catheter as a scaling device. To standardize the method of angiographic analysis, the following measures were taken: All study frames selected for analysis were end-diastolic to minimize motion artifact, and arterial segments were measured between the same identifiable branch points at each stage of the procedure.

\begin{tabular}{|c|c|}
\hline & Number \\
\hline \multicolumn{2}{|l|}{ Location of narrowings } \\
\hline Left anterior coronary artery & 8 \\
\hline Right coronary artery & 6 \\
\hline Leff circumflex coronary artery & 9 \\
\hline \multicolumn{2}{|l|}{ Portion of artery stented } \\
\hline Ostial or major bifurcation site & 9 \\
\hline Middle segment & 14 \\
\hline \multicolumn{2}{|l|}{ Modified AHA/ACC classification* } \\
\hline Type A & 2 \\
\hline Type B1 & 6 \\
\hline Type B2 & 9 \\
\hline Type C & 6 \\
\hline \multicolumn{2}{|l|}{ Type of dissection before stent ${ }^{\dagger}$} \\
\hline Type A & 2 \\
\hline Type B & 4 \\
\hline Type C & 8 \\
\hline Type D & 1 \\
\hline Type $\mathrm{E}$ & 7 \\
\hline Type F & 1 \\
\hline \multicolumn{2}{|l|}{ TIMI flow before stent ${ }^{\ddagger}$} \\
\hline TIMI O & 1 \\
\hline TIMI 1 & 0 \\
\hline TIMI 2 & 8 \\
\hline TIMI 3 & 14 \\
\hline Thrombus before stent $\hat{s}^{\hat{s}}$ & 7 \\
\hline \multicolumn{2}{|l|}{ Reason for stenting } \\
\hline Threatened closure & 22 \\
\hline Acute complete occlusion & 1 \\
\hline
\end{tabular}

Study end points and definitions: The primary clinical end point of the study was the occurrence of any of the following adverse cardiac cvents: acute or subacute stent thrombosis, repeat intervention, coronary artery bypass surgery, myocardial infarction, or death. Procedural success was defined as technically successful deployment of the stent in the absence of an adverse cardiac event. Angiographic success was defined as a $<30 \%$ residual diameter stenosis after final deployment of the stent. Subacute thrombosis was defined as a stent thrombosis within 14 days of deployment. Acute clinical outcome included all cardiovascular events occurring within 1 month of stent deployment.

Statistical analysis: A paired Student's $t$ test was used to compare scquential changes at the same segment in the same patients. A p value $<0.05$ was considered significant.

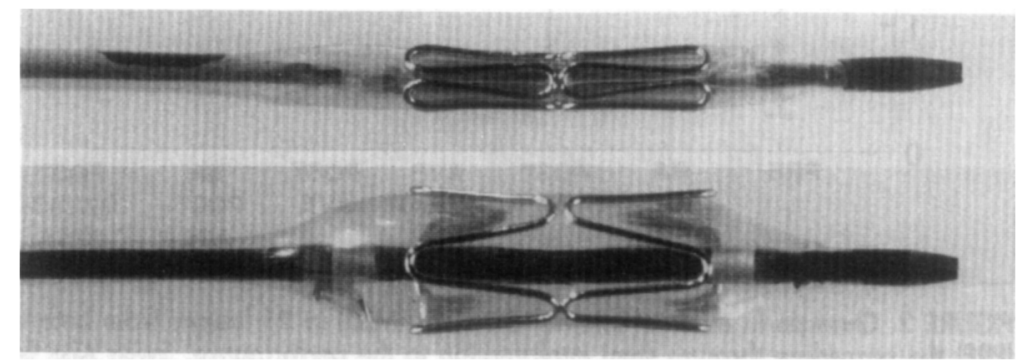

FIGURE 1. An $8 \mathrm{~mm}$ AVE Micro stent. The AVE Micro stent is a premounted balloon-expandable stainless steel stent composed of $4 \mathrm{~mm}$ welded or unconnected segments. 


\section{RESULTS}

Lesion characteristics: Angiographic characteristics of the treated lesions are listed in Table I. Of 23 lesions, 8 lesions were in the left anterior descending coronary arteries, 6 were in the right coronary arteries, and the remaining 9 were in the circumflex coronary arteries. Four of the lesions were ostial and 5 were at sites of major bifurcation. Before BA, the lesions were categorized according to the American Heart Association/American College of Cardiology Task Force crileria. ${ }^{25}$ Of the 23 lesions, 2 were type A, 15 were type $B$, and the remaining 6 were type $C$. After primary BA, at the time of acute or threatened vessel closure, 2 lesions had a type A dissection (with $>50 \%$ diameter stenosis), 4 a type B dissection (with $>50 \%$ diameter stenosis), 8 a type C, 1 a type D, 7 a type E, and 1 a type $F$ dissection. ${ }^{18}$ At this prestent phase, TIMI flow ${ }^{19}$ was grade 0 in 1 lesion, grade 2 in 8 , and grade 3 in 14 lesions, and the angiographic appearance of intracoronary thrombus (intraluminal filling defect) was present in 7 lesions. ${ }^{26}$

Procedural outcome: Stent delivery was possible in 27 of 28 stents (96\%). In 1 patient, the stent could not be advanced beyond an oblique curved branch point to the target stenosis in the midleft anterior descending artery. The unexpanded stent was withdrawn through the guiding catheter without difficulty and the patient was managed by emergency bypass surgery, after which the patient had no further event. In a second patient, a $12 \mathrm{~mm}$ stent was deployed at the origin of the left anterior descending artery. During the process of stent inflation, the proximal $4 \mathrm{~mm}$ unit of the $12 \mathrm{~mm}$ stent migrated proximally into the mainstem of the left coronary artery. This $4 \mathrm{~mm}$ unit was then expanded fully in the left mainstem and the patient had an uneventful clinical course.

In-hospital events: One patient in whom stent delivery was unsuccessful underwent emergency bypass surgery and had a normal postoperative recovery. The clinical course of the other 19 patients in whom stent de-

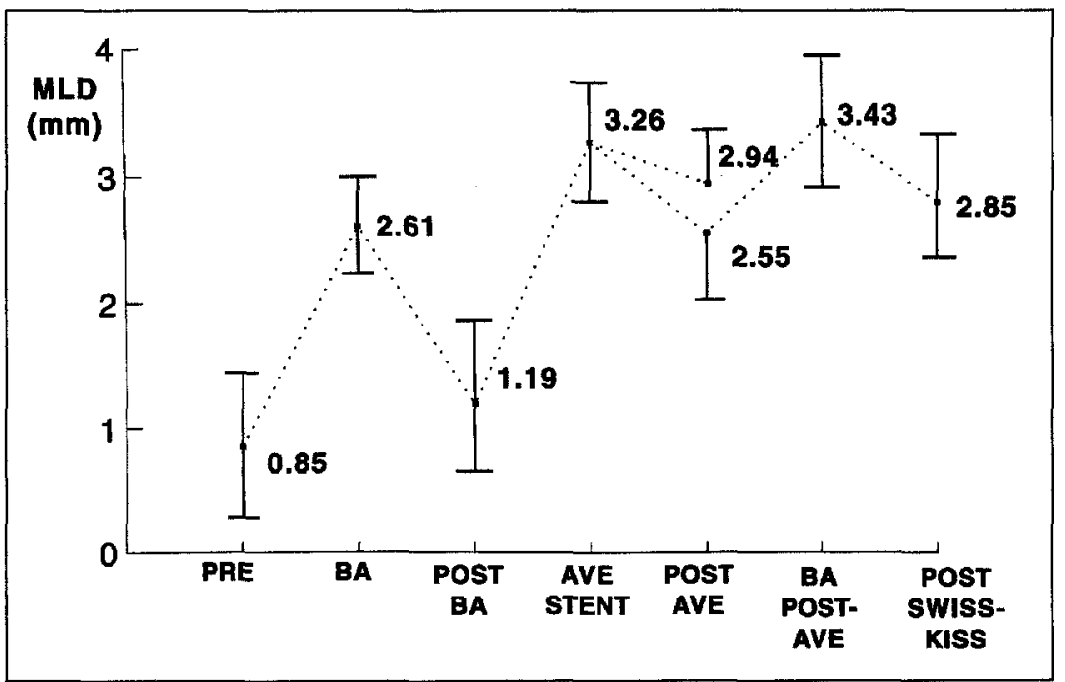

FIGURE 2. Changes in minimal luminal diameter (MLD) in 23 lesions from before (PRE) the procedure through stent implantation to the performance. Swiss Kiss (see text) was performed in 14 lesions. Minimal luminal diameter improved significantly after (POST) AVE stent implantation and after the performance of a Swiss Kiss (14.6 $\pm 3.5 \mathrm{~atm})$. BA = balloon angioplasty. ployment was successful was free of coronary reintervention, bypass surgery, and death. A myocardial infarction was observed in 2 patients (10\%), in 1 of whom the stent was implanted within 24 hours after the onset of acute myocardial infarction, and in the other patient acute vessèl occlusion was present for 58 minutes before stent implantation. A femoral hemorrhage and hematuria requiring blood transfusion were observed in $1 \mathrm{pa}-$ tient (5\%). All patients remained event free after hospital discharge, and thus the event-free survival at 30 days follow-up was $85 \%$ (17 of 20 patients).

Quantitative angiographic analysis: Quantitative angiographic analysis provided measurements of luminal diameter at each procedural phase. Minimal luminal diameter (MLD) was seen to change from $0.85 \pm 0.57 \mathrm{~mm}$ before primary BA to $1.19 \pm 0.66 \mathrm{~mm}$ after BA at the time of dissection. Implantation of the AVE Micro stent increased the MLD to $2.74 \pm 0.51 \mathrm{~mm}(\mathrm{p}<0.001)$. The changes in MLD from before primary BA through stent implantation to after Swiss Kiss are shown in Figure 2. In 14 lesions requiring poststent balloon dilatation (Swiss Kiss), the MLD increased significantly from $2.55 \pm 0.52$ $\mathrm{mm}$ (before Swiss Kiss) to $2.85 \pm 0.48 \mathrm{~mm}$ (after Swiss Kiss, $\mathrm{p}<0.01$ ). The absolute value of the acute stent recoil in the initial implantation (MLD during stent inflation, MLD after stent) was $0.52 \pm 0.30 \mathrm{~mm}$, and the acute recoil ratio of this stent (MLD during stent inflation, MLD after/during stent inflation) was $16 \pm 9 \%$. An examplc of the stent implantation in the disscction after BA can be seen in Figure 3. Angiographic success was achieved in all lesions with successful deployment of the stent. Thus, the angiographic success rate of all lesions attempted was $96 \%$ ( 22 of 23 lesions). Average percent diameter stenosis decreased significantly from $69 \%$ before intervention to a final residual value of $17 \%$ after stent deployment. Figure 4 shows the sequential changes in percent diameter stenosis. Performance of a Swiss Kiss in 14 lesions achieved a further reduction in residual percent diameter stenosis from $21 \%$ after AVE to $15 \%$ after Swiss Kiss $(\mathrm{p}<0.05)$.

\section{DISCUSSION}

The key findings of this early experience were as follows: (1) Delivery of the AVE Micro stent to the target lesion can be achieved in a high proportion of cases ( 22 of 23 lesions). (2) After delivery of the stent (22 lesions), angiographic success as defined by $<30 \%$ residual diameter stenosis can be achieved in a high proportion of cases (22 of 22). (3) Acute recoil after dilatation of the Micro stent in vivo compares favorably with other stents. ${ }^{27,28}$ (4) Despite the bailout indication for stenting, deployment of the Micro stent resulted in a low risk of acute or subacute stent thrombosis ( 0 of 22 stented lesions).

Successful delivery of the Micro stent may be attributed to 2 characteristics of the stent design. First, the 1.65 $\mathrm{mm}$ profile of the Micro stent in its 
unexpanded balloon-mounted state compares favorably with that of previous stents, and thus an intraprocedural exchange of the guiding catheter or guidewire should rarely be necessary. Second, the unconnected junctions of the modules and the 4 and $8 \mathrm{~mm}$ length of the individual modules provide the stent with hinge joints and very limited rigid segments to aid the negotiation of tortuous vessels. Furthermore, these 2 features, in conjunction with the primarily longitudinal orientation of the stent struts, should permit passage of an additional Micro stent through a proximally placed stent when necessary. The proximal migration during inflation of a $4 \mathrm{~mm}$ segment of an unconnected $12 \mathrm{~mm}$ stent into the left mainstem in 1 of our patients, indicates that only connected (welded) units of the AVE Micro stent should be placed in ostial lesions to prevent such an occurrence.

Although 21 of 23 lesions had dissection type $\mathrm{B}, \mathrm{C}, \mathrm{D}, \mathrm{E}$, and $\mathrm{F}$ after primary $\mathrm{BA}$, stenting was effective in tacking back the dissection flap and restoring TIMI 3 flow in all lesions stented. Although 7 of the lesions with threatened closure had angiographic evidence of intracoronary thrombus before stenting, deployment of the Micro stent without the administration of intracoronary thrombolytic therapy resulted in neither acute nor subacute thrombosis during follow-up. The absence of stent thrombosis may relate to the low metallic surface area of the Micro stent $(8.4 \%$ for the $3.5 \mathrm{~mm}$ stent in the expanded state) and the optimal expansion of the stent $(<30 \%$ residual diameter stenosis in all stented lesions), with the additional performance, when necessary, of a Swiss Kiss. ${ }^{29}$

Two of our patients (10\%) had significantly elevated creatine phosphokinase levels and electrocardiographic changes in myocardial infarction. In 1 of these 2 patients, stent implantation was performed within 24 hours of the onset of an acute Q-wave myocardial infarction, and the patient became asymptomatic after stenting and creatine phosphokinase levels continued to decline after stenting without a further increase. In the other patient, acute vessel closure had been present for 58 minutes before stent deployment. This patient had no further chest pain after stent implantation and the peak creatine phosphokinase level in this patient was $720 \mathrm{IU} / \mathrm{L}$. Lincoff et $\mathrm{al}^{9}$ indicated that peak creatine phosphokinase levels directly related to the time of stent placement after the onset of vessel closure and significant creatine phosphokinase elevation was frequently ob-

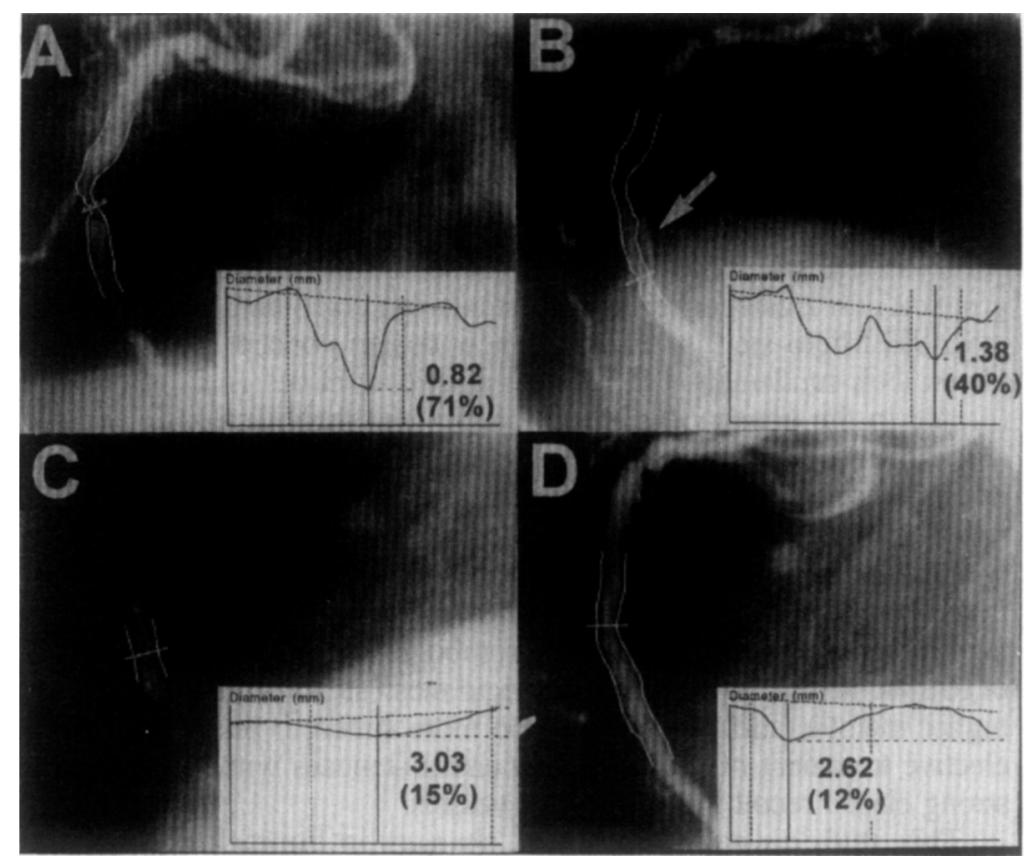

FIGURE 3. Coronary angiography of the right coronary artery in a patient with dissection after primary balloon angioplasty. Before balloon angioplasty, the minimal luminal diameter (MLD) was $0.82 \mathrm{~mm}$ (A). After balloon angioplasty, the MLD increased to $1.38 \mathrm{~mm}$; however, a type $C$ dissection with Thrombolysis in Myocardial Infarction trial III flow was present (B). Two AVE Micro stents (each 3 $\mathrm{mm}$ in diameter and $8 \mathrm{~mm}$ in length) were deployed and the moderately radiopaque stent struts can be seen during inflation of the stent (C). After stent deployment, the MLD improved to $2.62 \mathrm{~mm}$ with resolution of the dissection (D). served when vessel closure persisted for $>49$ minutes. Thus, the elevated creatine phosphokinase levels in our 2 patients were believed to reflect their clinical events before stent deployment rather than the occurrence of an acute or subacute thrombosis after stenting.

Both single center and multicenter observational series of bailout stenting have been reported for the Wallstent ${ }^{6}$ Palmaz-Schatz stent, ${ }^{7-11}$ and Gianturco Roubin stent. ${ }^{12-14}$ These have been associated with a deployment success

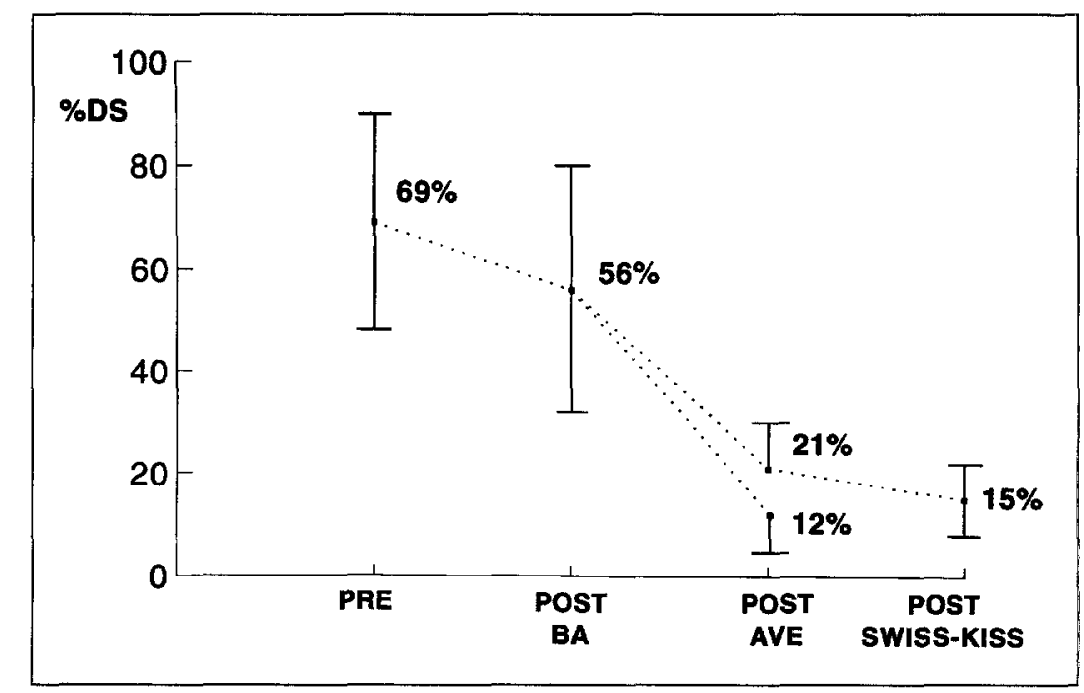

FIGURE 4. Changes in percent diameter (\%DS) stenosis from before (PRE) the procedure to after (POST) stent implantation in 23 lesions. A Swiss Kiss with high pressure $(14.6 \pm 3.5 \mathrm{~atm})$ was performed in 14 lesions and the percent diameler stenosis improved from $21 \%$ to $15 \%$. BA = balloon angioplasty. 
rate of $89 \%$ to $98 \%$, a myocardial infarction rate of $4 \%$ to $43 \%$, a bypass surgery rate $1 \%$ to $60 \%$, a subacute thrombosis rate $7 \%$ to $16 \%$, and a mortality rate of $1 \%$ to $7 \%$. More recently, a number of new stents have become available for clinical evaluation; these include the Cordis and Advanced Cardiovascular Systems stents. Whereas the structural design of these stents can be grouped into 2 categories of mesh stents and coil stents, the AVE Micro stent represents a new design concept. Given their fundamental differences in structural design (profile in the unexpanded state, longitudinal flexibility, mechanism of deployment, metallic surface area in the expanded state, interstrut distance, strut orientation, and radial strength), each stent will have to prove its own safety and efficacy for each clinical indication in prospective trials. It is likely that stents with a low metallic surface may be more suited to the more thrombogenic substrate of bailout stenting, while the more rigid mesh stents with higher metallic surface area may be more suited to the elective treatment of primary or recurrent stenoses with strong elastic recoil in nontortuous vessels.

This study revealed sequential changes in luminal diameter from before primary intervention, through stent implantation, to the performance of a Swiss Kiss. Percent diameter stenosis decreased from $69 \%$ (before BA) through 56\% (after BA) to 15\% (after Swiss Kiss). Whereas previous in vitro testing of this stent has found recoil to be $8.7 \%$ for the $3.5 \mathrm{~mm}$ diameter stent, in this quantitative angiographic study of the stent in diseased coronary arteries in vivo, we found recoil to be $16 \pm 9 \%$ $(0.52 \mathrm{~mm})$, with an average stent diameter of $3.41 \mathrm{~mm}$. Furthermore, the poststent MLD achieved matched or was greater than the nominal stent size in only 3 of 22 stented lesions. The performance of a high-pressure (14 atm) Swiss Kiss may result in an increase in MLD by $0.31 \mathrm{~mm}$, and may be a useful complementary technique when on-line quantitative angiographic analysis is available to guide the optimization of stent deployment.

Acknowledgment: We gratefully acknowledge Eline Montauban van Swijndregt for her preparation of the figures.

1. Dretre KM, Holmes DR, Holubkov R, Cowley MJ, Bourassa MG, Faxon DP, Dorros GK, Bentivoglio LG, Kent KM, Myler RK. Incidence and consequences of periprocedural occlusion: The 1985-1986 National Heart, Lung, and Blood Institute Percutaneous Transluminal Coronary Angioplasty Registry. Circulation 1990; 82:739-750.

2. de Feyter PJ, van den Brand M, Jaarman GJ, van Domburg R, Serruys PW, Suryapranata $\mathrm{H}$. Acute coronary artery occlusion during and after percutaneous transluminal coronary angioplasty. Frequency. prediction. clinical course. management and follow-up. Circulation 1991;83:927-936.

3. Lincoff AM, Popma JJ, Ellis SG, Hacker JA, Topol EJ. Abrupt vessel closure complicating coronary angioplasty: clinical, angiographic and therapeutic profile. J Am Coll Cardiol 1992;19:926-935.

4. Stammem F, Piessens J, Vrolix M, Glazier JJ, De Geest H, Willems JL. Immediate and short-term results of a 1988-1989 coronary angioplasty registry. Am J Cardiol 1991;67:253-258.

5. Sigwart U, Urban P, Golf S, Kaufmann U, Imbert C, Fisher A, Kappenberger L. Emergency stenting for acute occlusion after coronary balloon angioplasty. Cir. culation 1988;78:1121-1127.

6. de Feyter PJ, DeScheerder I, van den Brand M, Laarman GJ, Suryapranata H,
Serruys PW. Emergency stenting for refractory acute coronary occlusion during coronary angioplasty. Am J Cardiol 1990;66:1147-1150.

7. Roubin GS, Cannon AD, Agrawal SK, Macander PJ, Dean LS, Baxley WA, Breland J. Intracoronary stenting for acute and threatened closure complicating percutaneous transluminal coronary angioplasty. Circulation 1992;85:916-927.

8. Hearn JA, King SB, Douglas JS, Carlin SF, Lembo NJ, Ghazzal ZMB. Clinical and angiographic outcome after coronary artery stenting for acute or threatened closure after percutaneous transluminal coronary angioplasty. Initial results with a balloon-expandable, stainless steel design. Circulation 1993;88:2086-2096.

9. Lincoff AM, Topol EJ, Chapekis AT, George BS, Candela RJ, Muller DW, Zimmerman CA, Ellis SG. Intracoronary stenting compared with conventional therapy for abrupt vessel closure complicating coronary angioplasty: a matched case-control study. J Am Coll Cardiol 1993;21:866-875.

10. George BS, Voorhees WD, Roubin GS, Fearnot NE, Pinkerton A, Raizner AE, King SB, Holmes DR, Topol EJ, Kereiakes DJ, Hartzler GO. Multicenter investigation of coronary stenting to treat acute or threatened closure after percutaneous transluminal coronary angioplasty: clinical and angiographic outcomes. J Am Coll Cardiol 1993;22:135-143.

11. Sutton JM, Ellis SG, Roubin GS, Pinkerton GA, King SB, Raizner AE, Holmes DR, Kereiakes DJ, Topol EJ, for the Gianturco-Roubin Intracoronary Stent Investigator Group. Major clinical events after coronary stenting, the multicenter registry of acute and elective Gianturco-Roubin stent placement. Circulation 1994;89: $1126-1137$.

12. Herrmann HC, Buchbinder M, Clemen MW, Fishman D, Goldberg S, Leon MB, Schatz RA, Tierstein P, Walker CM, Hirshfeld JW. Emergent use of balloonexpandable coronary artery stenting for failed percutaneous transluminal coronary angioplasty. Circulation 1992;86:812-819.

13. Haude M, Erbel R, Straub U, Dietz U, Schatz R, Meyer J. Results of intracoronary stents for management of coronary dissection after balloon angioplasty. Am J Cardiol 1991;67:691-696.

14. Schomig A, Kastrati A, Mudra H, Blasini R, Schuhlen H, Klauss V, Richardt G, Neumann FJ. Four-year experience with Palmaz-Schatz stenting in coronary angioplasty complicated by dissection with threatened or present vessel closure. Circulation 1994;90:2716-2714.

15. Serruys PW, Keane D. The bailout stent. Circulation 1993;88:2455-2457.

16. Keane D, Roubin G, Marco J, Feamot N, Serruys PW. GRACE-Gianturco Roubin stent in acute closure evaluation: substrate, challenges and design of a randomized trial of bailout therapy. I Interven Cardiol 1994;7:333-339.

17. Braunwald E. Unstable angina. A classification. Circulation 1989;80:410-414. 18. Huber MS, Mooney JF, Madison J, Mooney MR. Use of a morphologic classification to predict clinical outcome after dissection from coronary angioplasty. Am I Cardiol 1991;68:467-471.

19. The TIMI Study Group. The Thrombolysis in Myocardial Infarction (TIMI) trial. N Engl J Med 1985;312:932-936.

20. Serruys PW, deJaegere P, Kiemeneij F, Macaya C, Rutsch W, Heyndrickx G, F.manuelsson $H$, Marco J, I egrand V, Materne P, Relardi I, Sigwart $U_{\text {, Colombo }}$ A, Goy JJ, van den Heuvel P, Delcan J, Morel MA, for the Benestent Study Group. A comparison of balloon-expandable-stent implantation with balloon angioplasty in patients with coronary artery disease. $N$ Engl J Med 1994;331:489-495.

21. Haase J, Escaned J, van Swijndregt EM, Ozaki Y, Gronenschild E, Slager CJ, Serruys PW. Experimental validation of geometric and densitometric coronary measurements on the new generation cardiovascular angiography analysis system (CAAS II). Cathet Cardiovasc Diagn 1993;30:104-114.

22. Gronenschild E, Janssen J, Tijdens F. CAAS II: a second generation system for off-line and on-line quantitative coronary angiography. Cathet Cardiovasc Diagn 1994;33:61-75.

23. Sernus PW, Foley DP, de Feyter PJ, eds. Quantitative Angiography in Clinical Practice. Dordrecht: Kluwer Academic, 1993:317-328.

24. Ozaki Y, Keane D, Herrman JP, Foley D, Haase J, den Boer AD, Di Mario C, Serruys PW. Coronary arteriography for quantitative analysis: an experimental and clinical comparison of cinefilm and video recordings. Am Heart $J$ 1995;129: $471-475$.

25. Ryan TJ, Faxon DP, Gunnar RM, Kennedy JW, King SB III, Loop FD, Peterson KL, Reeves TJ, Williams DO, Winters WL Jr. Guidelines for percutaneous transluminal coronary angioplasty: a report of the American College of Cardiology/American Hcart Association Task Force on assessment of diagnostic and therapentic cardiovascular procedures (subcommittee on percutaneous transluminal coronary angioplasty). Circulation 1988;78:486-502.

26. Capone G. Wolf NM. Meyer B. Meister SG. Frequency of intracoronary filling defects by angiography in angina pectoris at rest. Am J Cardiol 1985;56: 403-406.

27. Popma JJ, White C, Pinkerton CA, Ramee S, Keller MB, Leon MB. Effect of balloon expandable stent design on vascular recoil and lesion site morphology after intracoronary placement (abstr). Circulation 1992;86(suppl I):I-332.

28. Keane D, Ozaki Y, Baptista J, Di Mario C, deJaegere P, Haase I, Serruys PW. Stcnt sizing should make allowance for both inhomogcnous inflation and recoil (abstr). J Am Coll Cardiol 1994;23(suppl):73A.

29. Colombo A, Hall P, Nakamura S, Almagor Y, Maiello L, Martini G, Gaglione A. Goldberg SL. Tobis JM. Intracoronary stenting without anticoagulation accomplished with intravascular ultrasound guidance. Circulation 1995;91:1676-1688. 